\title{
Analysis on the Concepts of Systemic Equipment Support Peng Yang ${ }^{1, a}$, Xinliang Yan ${ }^{2, b}$, Tielin Liu ${ }^{1, c}$ \\ ${ }^{1}$ School of Ordnance Engineering College, Shijiazhuang 050003, China. \\ ${ }^{2}$ Section of Military Deputies in Jinzhong, Jinzhong 030812, China. \\ a364832960@qq.com, b398328970@qq.com,c1032759310@qq.com.
}

Keywords: System of Systems, Equipment, Systemic Support.

\begin{abstract}
The mode of modern war in the information age, is actually a war between systems of systems (hereinafter referred to as SOS), in which, systemic equipment support obviously constitutes a crucial part. Based on the fact that there is so far no consensus on the concept of systemic equipment support, to meet future operation requirements, this paper intends to analyze the concepts of systemic equipment support, set force its great importance in modern war, and propose the future direction of the mode of modern war.
\end{abstract}

\section{Introduction}

In recent years, the models of war get more and more systemic features throughout the world. In this context, it is imperative to ensure the construction and development of the equipment support is systemic. Nowadays, the systemic support of equipment is a new issue. And the research of it is still in an exploratory stage. In this paper, we will focus on systemic combat in the future, the concept of weapons and equipment to support the concept of a systematic combing and review. Now we have an analysis of the concept of systemic equipment support in a tentative way.

\section{System of Systems}

\subsection{Origin and Development of the SOS}

Along with the progress of science and information network, our life has become more and more convenient. The small individual things get from independent to closely linked in life. In fact, the boundaries of these small systems are indeed in fuzzy fusion, they are evolving into a complex organic whole, and this is the system of systems.

"System of systems" is abbreviated to "SOS", the article named "Cities as systems within Systems of Cities" in "REFERENCE OF NEW YORK CITY" first put this version in 1964. Then various systems emerge out, but they are basically independent existence and operation, the interface between them is not uniform, turning out the formation of a lot of "island" and "chimney" in the process of social informational construction. To combine these systems closely and efficiently, the conception of SOS is further defined as which we reach a consensus now. The appearing of this concept caused a lot of discussion immediately, the disputes include SOS is either specific physical or an abstract concept, is it a product of the information age technology progress or innate, the difference and the connection between the SOS with large scale system, complex system, integrated system and so on.

As a field and direction of scientific research, the SOS has been accepted by the biology and sociology first. At this present day, on account of its characteristics of universality, relevance and permeability, SOS exist in our life, and various aspects of space field, its range covers from biological organism to human social organization, economic organization, system of city traffic, military organization and so on. In simple terms, the problems that involve multiple complex systems can be attributed to the category of system problems.

\subsection{Definition of SOS}

We will not be unfamiliar with the concept of "SOS", it is widespread in both written and oral expression in our daily social life. So what is the exact meaning of it? "The modern Chinese 
dictionary" defines the "SOS" as "a certain number of things or some of the awareness of each other to form a whole". "The Encyclopedia of the Soviet Union" defined it as "a collection of elements of a system that are interrelated and interrelated and constitute a whole".

Further specifically, in accordance with the concept of system scientific which established by Bertalanffy in 20th century, "SOS" is an organic whole which is a system of certain things or consciousness restrict contacting with each other, and it is provided with some special functions. The SOS is integrated by the large and complex and independent systems, but not all the collection of systems or complex systems can be identified as a SOS, only those which the function of it is fully reflecting of the will of people, reflecting people's purpose and intent, can be called SOS. The subsystems work together to achieve the goal, and it is not a simple superposition of the function of the system, but by the way of "man in the loop" to adjust and evolve over time, through their respective authority to provide the ability to complete the mission.

The previous summary of SOS's main features are: A Composed of large scale, complex structure, there are integration and cooperation among the subsystems; B Widely distributed systems, every subsystem has its own unique features and independent management; C Subsystems need work together to fulfill the task, and mutual operation can be performed at the same time; D The task of SOS is not fixed, it can allocate resources dynamically to achieve a variety of needs; E By its function of emergence, it should centralized management and planning in the process of development and achieve the emergence of new behavior and functionality; F The ability of coordinating with other stakeholders to achieve the common goal.

\subsection{Interpretation of SOS in Military Field}

Because of the complexity of its emergence and the complexity of its composition, the definition of the system is not same in different fields and applications. The classical definition of the SOS in the military literature at home and abroad is shown in Table 1

Table 1. Classical definition of SOS in military field at home and abroad

\begin{tabular}{|c|c|}
\hline Domain & Classical Definition \\
\hline $\begin{array}{l}\text { Military systems and space } \\
\text { exploration }\end{array}$ & $\begin{array}{l}\text { SOS is composed of heterogeneous network integration system in the } \\
\text { distributed environment, and these heterogeneous systems possess } \\
\text { independent operation, independent management and regional } \\
\text { distribution characteristics, when the interactions of subsystems are } \\
\text { considered separately, the emergence and evolution of SOS is not } \\
\text { obvious. }\end{array}$ \\
\hline $\begin{array}{l}\text { United States Department } \\
\text { of Defense }\end{array}$ & $\begin{array}{l}\text { SOS is an independent system collection or array which connected to } \\
\text { achieve the specified capacity, the overall capacity will seriously absent } \\
\text { when any part of it is lack, it can realize the ability of independent } \\
\text { association system collection or array in multifarious ways. }\end{array}$ \\
\hline $\begin{array}{l}\text { The integration of modern } \\
\text { military system to gain the } \\
\text { information superiority and } \\
\text { decision superiority }\end{array}$ & $\begin{array}{l}\text { The SOS is a connection of system, which allows the system to } \\
\text { cooperate and collaborate with each other, such as C4I (Command, } \\
\text { Control, Computers, Communications, and Information) and ISR } \\
\text { (Intelligence, Surveillance and Reconnaissance). }\end{array}$ \\
\hline $\begin{array}{l}\text { Integrated field of } \\
\text { battlefield environment } \\
\text { information system }\end{array}$ & $\begin{array}{l}\text { The SOS is the synthesis of the system, and it is based on the } \\
\text { development, coordination and optimization. }\end{array}$ \\
\hline $\begin{array}{l}\text { The air defense system, the } \\
\text { missile defense system of } \\
\text { theater, the combat group }\end{array}$ & $\begin{array}{l}\text { The composition of SOS is different from the internal structure of the } \\
\text { general system, it is interactive between system and system. It has the } \\
\text { following characteristics: (1) It can provide more or stronger function } \\
\text { which a single integrated system short of; (2) The composition of the } \\
\text { system is able to operate independently, and it can play its functions in } \\
\text { the environment of SOS. }\end{array}$ \\
\hline
\end{tabular}




\section{Systematic Support}

\subsection{Concept of Systematic Support in Different Fields}

At present, systematic support has become a hot issue which concerned by many scholars and experts, but there is not a consensus reached a high level of definition. At first we arrange the concept of systematic support in different fields and draw upon all useful opinions.

The article of "Analysis on the systematic support ability of meteorological and hydrological based on information system" mentioned in the text that "meteorological and hydrological protection system is composed of various elements of support, support unit, support system, in accordance with the organizational structure of a joint operational guarantee system, follow the same mechanism of the overall operation." [1]

The article of "Analysis on the systematic support capacity of armored equipment based on information system" mentioned that "systematic support system of armored equipment refers to basing on the information system and the basic network support to armored vehicles as the main object of protection, in order to maintain a stable release of armored vehicle combat base wood, through the combination of various security methods. The related elements of combat system in armored equipment system support activities integrated into an organic whole, making the single arms and internal troops have real-time interaction, synchronous sharing of armored equipment support ability system." [2]

"To improve and accelerate the transformation of support force generation model of information system support system" mentioned "systematic support capacity based on information system, as the name implies, is that the integrated electronic information system is based on the support forces, support units and support element distributed in the various elements of the multidimensional space integration as a whole a seamless link to carry out combat security system." [3]

"Enhancing the Air Force logistical synthetic services" mentioned in the text that "the systematic support capacity is all of the of the logistics of the operation command and control unit, power unit and security defense logistics unit related to the protection, realize seamless link through the information link function and come into being integrated support SOS to maximize the support potential to achieve value-added effect."[4]

\subsection{Concept of Systematic Support}

Based on the above we can conclude that: the systematic support is refers to by the will of the people as the dominant purpose, with the support of the information network, the subsystems is the main support forces, in order to maintain the SOS stable and efficient output as the basic purpose, by combined application of various support methods to achieve make the support power, support unit and support elements integrated into an organic whole, the system of each subsystem has the capability of synchronous sharing to maximize the potential security force and carry out security task activity reflected in the purpose and premise of people.

Systematic support is not only a mode of support but also an ability of support. The systematic support is the support ability which formed of various support forces by the support of the information network. This is a new capability which is no longer a simple addition of a single support unit or a single support system, since it is too difficult for any single support force to fulfill complex tasks on its own. Systematic support no longer emphasizes the protection ability of a single support system, but assembling the subsystems into an organic whole to maximize the overall efficiency by effective using of information network technology.

\section{Systematic support of Equipment}

\subsection{Concept of Systematic support of Equipment}

Systematic support of equipment refers to the will of the people as the dominant purpose, with the support of information network, the subsystems are the main support force, fighting for the basic purpose of efficient and stable release in order to maintain the equipment system of main body, through the use of a combination of various security methods, security forces, security unit and security 
elements of the equipment support system integrated into an organic whole, so that the internal subsystems capable of synchronous interactive, real-time sharing, to maximize the protection potential, reflect people's purpose and attempt to carry out the safeguard military action task activity.

The key of systematic support of equipment is integrating today's advanced information network technology into all aspects of equipment support action, so the equipment support action will be an organic link, we should ensure that there is real-time communication among in the protection of power equipment and all levels of command and combat command and logistics system, all forces can share information of equipment support in real time in the military operations to the formation of a decision network equipment support to ensure the security action in precise control.

\subsection{Importance of Systematic Support of Equipment}

The equipment support must satisfy the conditions of informational combat needs, in the future environment is extremely complex, multi-dimensional battlefield space covering the sea, air and space electromagnetic, when combat become into a confrontation between SOS, only systematic support of equipment can cater to systematic operations' requirement. So we should consider the systematic support of equipment issues from the application of SOS and systematic support to meet the needs of systematic operations based on information system.

On one hand, it is determined by the systematic operations based on information network. Support service to combat, we need to break the traditional concept of support thinking for combat system under the conditions of information, make overall systematic support to meet the fast-paced and high-intensity systematic operations. Only support meet the system of confrontation operations' needs, combining the ideology of equipment systematic support and support operations to form the effective equipment support SOS to get the maximum efficiency of the support equipment.

On the other hand, it is decided by the systematic development of support equipment. At present, with all kinds of high technology into the equipment development, and careful layout and top-level design, support equipment is toward a direction of systematic development, but the most research of equipment support is remain the level about a single one or a single set, and the research of equipment systematic support has not got enough attention. A single equipment's broken down will affect the entire weapon system, we must ensure that the entire equipment system is in a good condition to be able to play the effectiveness of equipment.

\subsection{Development Direction of Systematic Equipment Support}

At present, there are three main problems in the development of the systematic support of equipment. First, the integration of current support modes. Combing the relationship between the support modes, We should use the existing technical means to achieve the resource integration of existing support systems, analysis the effectiveness of support and determining the ability to provide a basis for the next phase of the development of new support system; Second, planning of new support model. Repair of defects existing in the security system, strengthen internal system integration, making the communication of the support forces unit which in the support system more closely to achieve a new integration; Third, construction of the new support system. On the basis of the first two steps, constructing a new system of support model, it can achieve a new equipment systematic support model by compromising information exchange, business distribution and function modules into a true whole and becoming the organic combination of the internal system.

In fact, the studying of these problems is to achieve common prosperity of the two SOS, how develop the relationship between equipment system and systematic support, the latter one service the former one better and the former show the latter a specified way. Both of these are based on the SOS, so its development rules should follow the law of development of the SOS.

Construction of equipment systematic support is a new military affairs, it is the complicated system engineering. During its development process, there will be a lot of complexity and uncertainty because of the amalgamation of resources restructuring, information network system integration, so it is necessary to establish a global support concept. The key points of the systematic support are support theory, information network, system structure, support equipment and support personnel and so on. The construction of equipment systematic support must be close to the needs of the information 
battlefield. The precondition is strengthening the theoretical innovation of equipment support, the basis is building an information network platform, and forming an organization of systematic support. The research and development of informational support equipment is very important too, and speed up the high-quality personnel of equipment support, promoting a whole fusion of each part of the system of support equipment to maximize the effectiveness of equipment support system.

\section{References}

[1]. ZHAI Jianshe, WANG Yinhu, LI Na. Analysis on the Systematic Support Ability of Meteorological and Hydrological Based on Information System[J].Journal of PLA University of Science and Technology,2011,12 (1) :65-69.

[2]. LU Hongtao, ZHANG Xiong. Analysis on the systematic support capacity of armored equipment based on information system[J]. Journal of PLA University of Science and Technology, 2012, 13 (2):25-29.

[3]. WANG Zongquan, ZHU Zhiwei. To improve and accelerate the transformation of support force generation model of information system support system[J]. Journal of THE LOGISTICS COMMAND ACADEMY,2011(116):48-50.

[4]. JIAN Zangwang, CHEN Bing, WANG Bin, SU Jianmin. Enhancing the Air Force logistical synthetic services[J]. Journal of Xuzhou Air Force College, 2005, 16(4):8-10.

[5]. TAN Yueyin, ZHAO Qingsong. A Research on System-of-systems and System-of-systems Engineering[J]. Journal of CAEIT,2011,10(5):441-445.

[6]. MO JAMSHIDI. System of System Engineering Innovations or 21st Century [M]. New Jersey: Whey Hoboken, 2008. 